\title{
Kajian Kesesuaian Lahan Tambak Udang Vaname Dengan Menggunakan Sistem Informasi Geografis Di Desa Wonorejo, Kecamatan Kaliwungu, Kendal, Jawa Tengah
}

\author{
Annisa Amalia Awanis, Slamet Budi Prayitno*, Vivi Endar Herawati \\ Departemen Akuakultur Fakultas Perikanan dan Ilmu Kelautan, Universitas Diponegoro \\ Kampus Tembalang, Semarang 50275 Telp/Fax. 024-7474698 \\ Email : sbudiprayitno@gmail.com
}

\begin{abstract}
Abstrak
Desa Wonorejo, Kecamatan Kaliwungu, Kabupaten Kendal, Jawa Tengah memiliki suatu usaha budidaya udang vaname, untuk meningkatkan hasil produksi maka diperlukan usaha perluasan lahan budidaya, namun terdapat beberapa kendala dalam penentuan lokasi ini yaitu dibutuhkannya banyak biaya, waktu serta tenaga. Sistem Informasi Geografis (SIG) menjadi solusi yang tepat dalam penentuan lokasi yang sesuai untuk pengembangan budidaya udang vaname. Tujuan dari penelitian ini adalah untuk mengkaji kesesuaian lahan tambak udang vaname di Desa Wonorejo, Kecamatan Kaliwungu, Kabupaten Kendal, Jawa Tengah berdasarkan analisa SIG. Metode yang digunakan dalam penelitian adalah metode survey yaitu dengan cara pengukuran langsung ke lapangan dan wawancara dengan pembudidaya udang vaname. Data yang telah didapatkan diolah dengan menggunakan aplikasi ArcGis 10.0. Beberapa tahapan dalam pengolahan data yaitu pembuatan peta dasar, pembuatan peta kontur sebaran spasial dari setiap parameter, overlay, layout dan skoring. Data yang dihasilkan berupa model spasial. Analisa kesesuaian perairan dilakukan dengan pembuatan matriks kesesuaian kemudian pembobotan dan perhitungan skor berdasarkan tingkat pengaruh dari setiap parameter terhadap daerah yang berpotensi untuk budidaya udang vaname. Hasil yang didapatkan pada penelitian ini adalah suhu berkisar antara $27,86-29,5^{\circ} \mathrm{C}$, salinitas berkisar antara $10-20$ ppt, kedalaman berkisar antara 100-140 cm, kecerahan berkisar antara 20-40 cm, pH berkisar antara 7,9-8,5, DO berkisar anatara 3,67-6,67 mg/l, nitrat berkisar antara 4,8210-74,7669 mg/l dan fosfat berkiar antara 0,0394-0,0758 mg/l. Kesimpulan yang dapat diambil adalah bahwa secara umum kondisi perairan di Wonorejo, Kecamatan Kaliwungu, Kabupaten Kendal dapat mendukung usaha budidaya udang vaname. Total luas wilayah tambak di Wonorejo adalah 13,6 ha, dari luasan wilayah yang diamati 2 ha tergolong kedalam kategori sesuai (S2) dan 13,4 ha tergolong kedalam kategori sangat sesuai (S3).
\end{abstract}

Kata kunci : Udang vaname, Sistem Informasi Geografis, Kualitas Air, Kebutuhan Oksigen

\begin{abstract}
Wonorejo is a village in Kaliwungu sub distinct, Kendal, Central Java. That one of the vaname shrimp products in the area. The high potential of brackishwater ponds resulted in the expansion of shrimp ponds. However, the expansion was not carreid out based on the scientific but merely based on the feeling of the farmers. Geographic Information System (GIS) was aim to alternatively overcome this problem, so that the potential suitable location could be applied. The aim of this methods was to study the suitability of shrimp ponds in Wonorejo village, Kaliwungu sub distinct, Kendal, Central Java based on GIS. The data was obtained through satelite (map). and interview with farmers and district measurements in field. The data was analysed by ArcGis 10.0. The analyses were implemented in 5 steps namely production of basic map, production of spartial control map of each parameters, overlayed,layout and score. Suitability analysis was done by calculating the score of parameter then presented with reference. The result showed that temperature ranges between $27,86-29,5^{\circ} \mathrm{C}$, salinity ranges between 10-20 ppt, depth ranges between 100-140 $\mathrm{cm}$, brightness ranges between 20-40 cm, pH ranges between 7,9-8,5, DO ranges between 3,67-6,67 mg/l, nitrat ranges between 4,8210-74,7669 $\mathrm{mg} / \mathrm{l}$, and fosfat ranges between 0,0394-0,0758 $\mathrm{mg} / \mathrm{l}$. In general shrimp pondsin Wonorejo Village, Kaliwungu, Kendal was suitable vaname cultivation. From total shrimp pond area in Wonorejo Village, Kaliwungu 13,6 Ha, $2 \mathrm{Ha}$ was classified as suitable (S2) and 13,4 Ha was classified as very suitable (S3).
\end{abstract}

Keywords: Vaname shrimp, Geographic Information System, Water Quality, Oxygen Need

*Corresponding author

buloma.undip@gmail.com http://ejournal.undip.ac.id/index.php/buloma

Diterima/Received : 04-05-2017

Disetujui/Accepted : 17-07-2017 


\section{PENDAHULUAN}

Kondisi geografis Indonesia sebagai negara kepulauan telah membuat udang sebagai primadona ekspor komoditas perikanan. Salah satu udang yang menjadi komoditas utama budidaya adalah udang vaname. Keunggulan udang vaname dibandingkan dengan udang lainnya yaitu pertumbuhannya lebih cepat, ukuran panen yang lebih seragam, relative tahan dengan serangan penyakit, dan cara budidayanya relative lebih mudah. Menurut Yasir (2013), bahwa udang merupakan primadona yang berpotensi ekspor, bahkan devisa Negara dari hasil perikanan lebih dari $50 \%$ berasal dari komuditas udang. Dengan demikian industri udang semakin menjanjikan, terlebih lagi dengan andalanya jenis udang vaname yang produktivitasnya mencapai 6-10 ton/ha/tahun.

Kegiatan budidaya udang vaname ini salah satunya dilakukan di Kabupaten Kendal. Secara geografis Kabupaten Kendal terletak diantara $190^{\circ} 40$ - $110^{\circ} 18^{\prime}$ Bujur Timur dan $6^{\circ} 32^{\prime}-7^{\circ} 24^{\prime}$ Lintang Selatan. Secara administrasi Kabupaten Kendal sendiri berbatasan dengan Laut Jawa di sebelah Utara, Kota Semarang di sebelah Timur, Kabupaten Batang di sebelah Barat dan Kabupaten Temanggung di sebelah Selatan.Luas tambak di wilayah Kabupaten Kendal mencapai 3.293 hektar. Produksi total udang pada tahun 2014 mencapai 592.219 ton, dengan komoditas udang vaname sebesar $70 \%$, udang windu sebesar $21 \%$ dan udang lainnya $9 \%$ (DKP, 2014). Sistem budidaya yang diterapkan di Desa Wonorejo, Kabupaten Kendal yaitu secara intensif. Kegiatan budidaya secara intensif ini memerlukan berbagai input budidaya seperti pakan, pupuk, kapur, benih udang, kicir air, plastic mulsa, peptisida dan pergantian air baru. Luasan lahan budidaya udang vaname di Desa Wonorejo yaitu 13,4 ha, luasan tambak $2000 \mathrm{~m}^{2}$ dengan padat tebar 140.000 . Plastik mulsa dan pagar bambu sebagai biosecurity agar udang terhindar dari predator. Kicir air sebagai aerasi untuk pengkayaan oksigen, kicir air yang digunakan pada setiap tambak antara 4-8 buah. Kapur ini digunakan jika terjadi hujan dan kapir yang digunakan yaitu kapur kapta, tohar dan hidrat.

Keberhasilan budidaya udang vaname sangat ditentukan oleh pemilihan lokasi. Aspek yang perlu diperhatikan adalah aspek perairan. Suatu lahan tambak layak digunakan jika memenuhi syarat-syarat tertentu agar kehidupan udang vaname tidak terganggu sehingga produksi tambak memberikan hasil yang memuaskan.
Untuk meyakinkan kondisi lingkungan dapat mendukung kegiatan budidaya udang vaname, maka perlu dilakukan kajian kesesuaian lahan berdasarkan syarat-syarat yang mempengaruhi kehidupan udang, keamanan dan kelangsungan budidaya. Kajian kesesuaian lahan perairan dilihat dari kualitas perairannya seperti suhu, salinitas, kedalaman, kecerahan, $\mathrm{pH}, \mathrm{DO}$, nitrat dan fosfat. Menurut Kingzet et al., (2002), menyatakan bahwa analisis kelayakan lahan dilakukan dengan memperhatikan beberapa faktor, meliputi: keterlindungan lokasi, kondisi kualitas perairan (fisik dan kimia), kesuburan perairan, ketersediaan benih alam, dan sosial infrastruktur.

Tujuan dari penelitian ini adalah untuk mengkaji kesesuaian lahan tambak udang vaname dan melihat ketersediaan oksigen di Desa Wonorejo, Kecamatan Kaliwungu, Kabupaaten Kendal, Jawa Tengah. Hasil penelitian ini diharapkan dapat memberikan informasi kepada para pembudidaya udang vaname dan pemerintah daerah setempat sehingga dapat digunakan untuk memprediksi potensi produksi tambak udang vaname di wilayah Kecamatan Kaliwungu dan menjadi acuan untuk tetap dikembangkan. Penelitian ini dilaksanakan pada bulan Oktober 2016, di wilayah pertambakan Kecamatan Kaliwungu, Kabupaten Kendal, Jawa Tengah. Titik pengambilan sampel tersebar di Desa Wonorejo.

\section{MATERI DAN METODE}

Metode yang digunakan dalam penelitian adalah metode survey. Metode ini merupakan suatu metode yang dilakukan untuk mendapatkan atau memperoleh fakta-fakta dari gejala-gejala yang ada. Metode survey ini dilakukan untuk mendapatkan data primer yang berupa data kualitas perairan, baik parameter fisika maupun kimia (Wibowo, 2006). Pengumpulan data dilakukan dengan cara pengukuran langsung ke lapangan dan wawancara dengan pembudidaya udang vaname. Data lapangan yang diperoleh tersebut kemudian diolah menggunakan software ArcGis 10.0 sehingga menghasilkan suatu model dasar peta tematik. Peta dasar tematik yang dihasilkan kemudian digunakan untuk mengevaluasi kelayakan tambak serta mengetahui perubahan yang terjadi, sehingga dapat menduga nilai potensi produksi tambak.

Analisa kesesuaian perairan dengan pembuatan matriks kesesuaian untuk parameter fisika dan kimia. Pembuatan kriteria atau matriks kesesuaian ini berdasarkan tingkat pengaruh dari 
setiap parameter terhadap daerah yang berpotensi untuk dijadikan kawasan tambak. Matriks atau kriteria yang digunakan dalam penelitian ini terdiri dari 8 paramater yaitu suhu, salinitas, kedalaman, kecerahan, $\mathrm{pH}$, DO, nitrat dan fosfat. Tingkat kesesuaian dibagi atas 3 kelas yaitu kelas S3 : Sangat Sesuai, kelas S2 : Sesuai dan kelas S1 : Sesuai Bersyarat. Matriks skoring dan pembobotan kesesuaian lahan budidaya udang vaname dapat dilihat pada Tabel 1 .

Tabel di atas merupakan tabel skoring dan pembobotan kesesuaian lahan budidaya udang vaname dari setiap parameter kualitas air yang meliputi parameter suhu, salinitas, kedalaman, kecerahan, $\mathrm{pH}$, DO, nitrat dan fosfat. Nilai skor didapatkan dari hasil perkalian antara nilai $(\mathrm{N})$ dan bobot (B). Pemberian nilai dilihat dari seberapa besar dampak parameter tersebut terhadap kegiatan budidaya. Skoring kesesuaian perairan Wonorejo, Kecamatan Kaliwungu, Kabupaten Kendal dapat dilihat pada Tabel 2.

Tabel diatas merupakan tabel hasil skoring kesesuaian perairan Wonorejo, Kecamatan Kaliwungu, Kabupaten Kendal. Tingkat kesesuaian tersebut dilihat dari total skor yang telah didapatkan. Tingkat kesesuaian perairan ini terbagi menjadi 3 kategori yaitu sangat sesuai (S3) yang berarti perairan tersebut sangat potensial dan tidak memiliki factor penghambat, sesuai (S2) yang berarti perairan tersebut sudah memenuhi persyaratan minimal dan sesuai bersyarat (S1) yaitu perairan tersebut mempunyai factor pembatas, dan perlu adanya perlakuan khusus.

Tabel 1. Skoring dan Pembobotan Kesesuaian Lahan Budidaya Udang Vaname

\begin{tabular}{|c|c|c|c|c|c|c|}
\hline No & Parameter & Kisaran & $\begin{array}{l}\text { Nilai } \\
(\mathrm{N})\end{array}$ & $\begin{array}{l}\text { Bobot } \\
\text { (B) }\end{array}$ & $\begin{array}{l}\text { Skor } \\
(\mathrm{NxB})\end{array}$ & Referensi \\
\hline \multirow{3}{*}{1} & \multirow{3}{*}{ Suhu $\left({ }^{\circ} \mathrm{C}\right)$} & $25-32$ & 3 & & 9 & \multirow{3}{*}{ New (2002) } \\
\hline & & $12-25$ & 2 & 3 & 6 & \\
\hline & & $<12$ atau $>32$ & 1 & & 3 & \\
\hline \multirow{3}{*}{2} & \multirow{3}{*}{$\begin{array}{l}\text { Salinitas } \\
\text { (ppm) }\end{array}$} & $10-20$ & 3 & & 9 & \multirow{3}{*}{$\begin{array}{l}\text { Widiatmaka et al } \\
\text { (2014) }\end{array}$} \\
\hline & & $20-35$ & 2 & 3 & 6 & \\
\hline & & $<10$ atau $>35$ & 1 & & 3 & \\
\hline \multirow{4}{*}{3} & \multirow{4}{*}{$\begin{array}{l}\text { Kedalaman } \\
\quad(\mathrm{cm})\end{array}$} & $70-120$ & 3 & & 6 & \multirow{4}{*}{$\begin{array}{l}\text { Romadhona et at } \\
\text { (2015) }\end{array}$} \\
\hline & & $80-110$ atau $120-150$ & 2 & 2 & 4 & \\
\hline & & $<70$ atau $>150$ & 1 & & 2 & \\
\hline & & $30-40$ & 3 & & 6 & \\
\hline \multirow[t]{2}{*}{4} & \multirow{2}{*}{$\begin{array}{l}\text { Kecerahan } \\
\quad(\mathrm{cm})\end{array}$} & $25-30$ atau $40-60$ & 2 & 2 & 4 & \multirow[t]{2}{*}{ Cahyono (2009) } \\
\hline & & $<25$ atau $>60$ & 1 & & 2 & \\
\hline \multirow[t]{3}{*}{5} & \multirow[t]{2}{*}{$\mathrm{pH}$} & $6-8$ & 3 & & 6 & \multirow{3}{*}{$\begin{array}{l}\text { Widiatmaka et } \\
\text { (2014) }\end{array}$} \\
\hline & & $4-6$ atau $8-9$ & 2 & 2 & 4 & \\
\hline & & $<4$ atau $>9$ & 1 & & 2 & \\
\hline \multirow[t]{4}{*}{6} & \multirow[t]{4}{*}{ DO (mg/l) } & $4-7$ & 3 & & 9 & \multirow{4}{*}{$\begin{array}{l}\text { Widiatmaka et at } \\
\text { (2014) }\end{array}$} \\
\hline & & $2,5-4$ & 2 & 3 & 6 & \\
\hline & & $<2,5$ & 1 & & 3 & \\
\hline & & $0,3-0,9$ & 3 & & 9 & \\
\hline \multirow[t]{3}{*}{7} & \multirow[t]{3}{*}{ Nitrat (ppm) } & $0,9-3,5$ & 2 & 3 & 6 & \multirow{3}{*}{$\begin{array}{c}\text { Ramadhani et al } \\
\text { (2016) }\end{array}$} \\
\hline & & $>3,5$ & 1 & & 3 & \\
\hline & & $>0,21$ & 3 & & 9 & \\
\hline \multirow[t]{2}{*}{8} & \multirow{2}{*}{$\begin{array}{c}\text { Phospat } \\
(\mathrm{mg} / \mathrm{l})\end{array}$} & $0,1-0,21$ & 2 & 3 & 6 & \multirow{2}{*}{$\begin{array}{c}\text { Ramadhani et al } \\
\text { (2016) }\end{array}$} \\
\hline & & $0,051-0,1$ & 1 & & 3 & \\
\hline
\end{tabular}

Tabel 2 . Skoring Kesesuaian Perairan Wonorejo, Kecamatan Kaliwungu, Kabupaten Kendal

\begin{tabular}{ccl}
\hline Total Skor & Tingkat Kesesuaian & \multicolumn{1}{c}{ Kualitas Perairan } \\
\hline $43-63$ & Sangat sesuai & Potensial, tidak mempunyai faktor penghambat \\
$21-42$ & Sesuai & Memenuhi persyaratan minimal \\
$<21$ & Sesuai bersyarat & Mempunyai factor pembatas, perlu perlakuan khusus \\
\hline
\end{tabular}

Sumber : (Wibowo, 2006) 


\section{HASIL DAN PEMBAHASAN \\ Penentuan Titik Sampling}

Pengambilan titik lokasi penelitian yang dilakukan di Desa Wonorejo, Kecamatan Kaliwungu, Kabupaten Kendal, Jawa Tengah sebanyak 7 titik, lokasi yang terpilih dapat mewakili daerah yang akan diteliti dan juga dengan beberapa pertimbangan seperti karakteriksik perairan tersebut, jarak antar stasiun 150-235 m, jarak tambak ke pantai $1,3 \mathrm{~km}$ dan juga untuk menghemat biaya, tenaga dan waktu. Hal ini diperkuat oleh pendapat Hartoko dan Alexander (2009) bahwa penentuan titik pengambilan sampel dilakukan secara purposive sampling atau dengan kata lain pengambilan secara sengaja dengan pertimbangan tertentu. Cara ini dimaksudkan agar lokasi yang terpilih dapat mewakili dari daerah yang akan diteliti. Pertimbangan dari penentuaan lokasi antara lain yaitu karakteristik perairan, jarak antar stasiun \pm 150-300 m, jarak tambak ke pantai antara 1-1,5 km. Lokasi Penelitian Di Desa Wonorejo, Kecamatan Kaliwungu, Kabupaten Kendal, Jawa Tengah (Gambar 1).

Tabel diatas merupakan tabel dari hasil pengukuran perairan di Desa Wonorejo, Kecamatan Kaliwungu, Kabupaten Kendal, Jawa Tengah. Hasil pengukuran suhu berkisar antara $27,86-29,5^{\circ} \mathrm{C}$. Suhu tertinggi terdapat pada titik 7 yaitu $29,5^{\circ} \mathrm{C}$, sedangkan nilai yang paling rendah terdapat pada titik 1 yaitu $27,86^{\circ} \mathrm{C}$. Salinitas berkisar antara 10-20 ppt, salinitas tertinggi terdapat pada titik 6 yaitu 20 ppt, sedangkan nilai yang paling rendah terdapat pada titik 1 yaitu 10 ppt.Kedalaman berkisar antara $100-140 \mathrm{~cm}$. Nilai kedalaman tertinggi terdapat pada titik 7 yaitu 140 $\mathrm{cm}$, sedangkan nilai yang paling terendah terdapat pada titik 2 yaitu $100 \mathrm{~cm}$. Kecerahan berkisar antara $20-40 \mathrm{~cm}$. Tingkat kecerahan tertinggi berada di titik 4 yaitu $40 \mathrm{~cm}$, sedangkan tingkat kecerahan terrendah terdapat pada titik 1 yaitu 20 cm.pH berkisar antara 7,9-8,5. Perbedaan

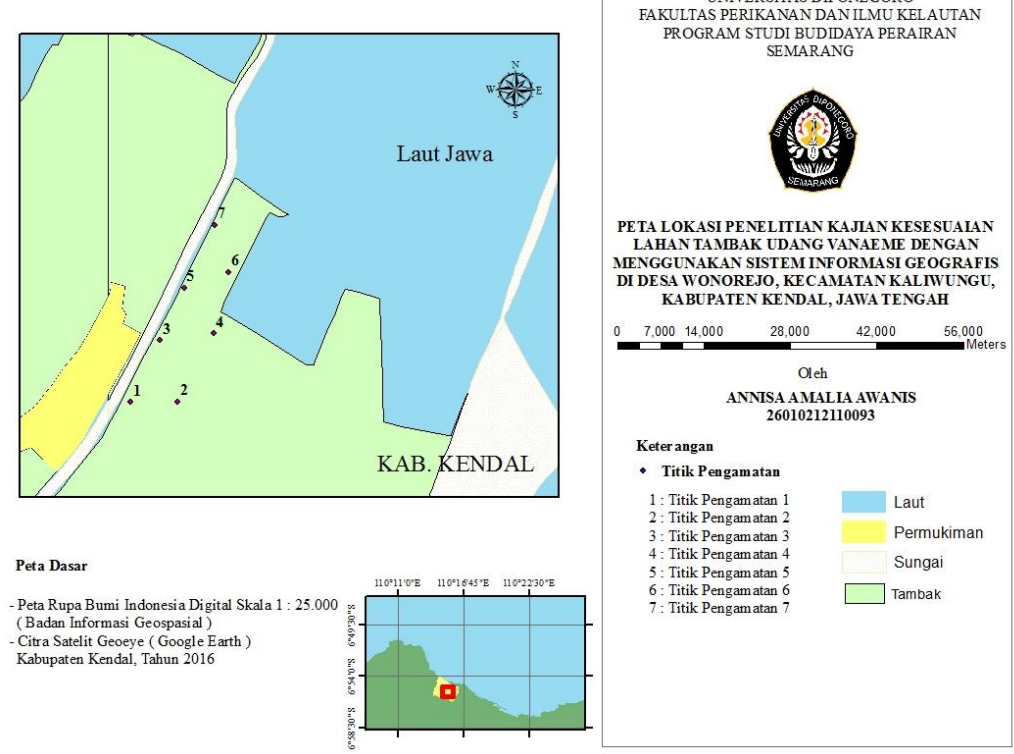

Gambar 1. Lokasi Penelitian Di Desa Wonorejo, Kecamatan Kaliwungu, Kabupaten Kendal, Jawa Tengah

Tabel 3. Hasil Pengukuran Perairan Di Desa Wonorejo, Kecamatan Kaliwungu, Kendal, Jawa Tengah

\begin{tabular}{|c|c|c|c|c|c|c|c|c|c|c|}
\hline \multirow[b]{2}{*}{ Titik } & \multicolumn{2}{|c|}{ Kordinat } & \multirow{2}{*}{$\begin{array}{l}\text { Suhu } \\
\left({ }^{\circ} \mathrm{C}\right)\end{array}$} & \multirow{2}{*}{$\begin{array}{l}\text { Salinitas } \\
\quad(p p t)\end{array}$} & \multirow{2}{*}{$\begin{array}{l}\text { Kedalaman } \\
\quad(\mathrm{cm})\end{array}$} & \multirow{2}{*}{$\begin{array}{l}\text { Kecerahan } \\
\quad(\mathrm{cm})\end{array}$} & \multirow[b]{2}{*}{$\mathrm{pH}$} & \multirow{2}{*}{$\begin{array}{c}\text { DO } \\
(\mathrm{mg} / \mathrm{l})\end{array}$} & \multirow{2}{*}{$\begin{array}{l}\text { Nitrat } \\
(\mathrm{mg} / \mathrm{l})\end{array}$} & \multirow{2}{*}{$\begin{array}{l}\text { Fosfat } \\
(\mathrm{mg} / \mathrm{l})\end{array}$} \\
\hline & $\begin{array}{l}\text { Lintang } \\
\left({ }^{\circ} \mathrm{LS}\right)\end{array}$ & $\begin{array}{c}\text { Bujur } \\
\left({ }^{\circ} \mathrm{BT}\right)\end{array}$ & & & & & & & & \\
\hline 1 & 6,927183 & 110,2507 & 27,86 & 10 & 110 & 20 & 8,3 & 3,67 & 74,7669 & 0,0673 \\
\hline 2 & 6,927175 & 110,2521 & 28 & 12 & 100 & 30 & 8 & 4,73 & 5,6176 & 0,0394 \\
\hline 3 & 6,925211 & 110,2516 & 28,23 & 16 & 120 & 30 & 8,5 & 5,48 & 18,0078 & 0,0758 \\
\hline 4 & 6,925111 & 110,2532 & 28,7 & 15 & 130 & 40 & 8,3 & 5,36 & 6,9156 & 0,0644 \\
\hline 5 & 6,923233 & 110,2523 & 29,06 & 14 & 115 & 35 & 7,9 & 5,14 & 5,4996 & 0,0508 \\
\hline 6 & 6,923244 & 110,2537 & 29,26 & 20 & 120 & 30 & 8,4 & 6,67 & 4,8210 & 0,0547 \\
\hline 7 & 6,921831 & 110,2533 & 29,5 & 16 & 140 & 35 & 8,4 & 6,42 & 5,5881 & 0.0445 \\
\hline
\end{tabular}


kandungan $\mathrm{pH}$ pada setiap titik penamatan tidak memiliki perbedaan yang drastis. DO berkisar anatara 3,67-6,67 mg/l. Nilai DO tertinggi terdapat pada titik 6 yaitu $6,67 \mathrm{mg} / \mathrm{l}$, sedangkan nilai yang paling rendah terdapat pada titik 1 yaitu $3,67 \mathrm{mg} / \mathrm{l}$. Hasil pengukuran nitrat berkisar antara 4,8210-74,7669 mg/l. Nitrat tertinggi terdapat pada titik 1 yaitu $74,7669 \mathrm{mg} / \mathrm{l}$, sedangkan nilai yang rendah terdapat pada titik 5 yaitu 4,8210 $\mathrm{mg} / \mathrm{l}$. Fosfat berkiar antara 0,0394-0,0758 mg/l. nilai fosfat tertingi terdapat pada titik 3 yaitu $0,0758 \mathrm{mg} / \mathrm{l}$, sedangkan nilai terendah terdapat pada titik 2 yaitu $0,0394 \mathrm{mg} / \mathrm{l}$.

\section{Analisis kesesuaian lahan}

Setelah mendapatkan data kualitas air berupa suhu, salinitas, kedalaman, kecerahan, $\mathrm{pH}, \mathrm{DO}$, nitrat dan fosfat kemudian data tersebut diolah menggunakan diolah menggunakan software ArcGis 10.0 untuk mendapatkan interpolasi. Total luasan perairan Wonorejo, Kecamatan Kaliwungu, Kabupaten Kendal adalah 13,6 ha. Hasil pembobot yang diperoleh dari hasil penelitian ini menunjukan keadan perairan masih sangat memenuhi syarat untuk melakukan kegiatan budidaya. Berdasarkan pembobotan, wilayah perairan yang termasuk kedalam kategori kategori S2 memiliki luas sekitar 2 ha. Wilayah dalam kategori S2 berada pada titik 1. Wilayah tersebut masuk kedalam kategori S2 dikarenakan wilayah ini memiliki parameter kualitas air yang sesuai untuk dijadikan sebagai lahan budidaya dan memenuhi persyaratan minimal untuk budidaya udang vaname. Wilayah perairan yang termasuk kedalam kategori S3 memiliki luas sekitar 13,4 ha. Wilayah dalam kategori S3 berada pada titik 2,3,4,5,6 dan 7. Wilayah tersebut masuk kedalam kategori S3 dikarenakan wilayah ini memiliki parameter kualitas air yang sangat sesuai untuk dijadikan sebagai lahan budidaya udang vaname dan tidak memiliki factor penghambat. Peta kesesuaian lahan budidaya udang vaname di Desa Wonorejo, Kabupaten Kendal dapat dilihat pada Gambar 2.

Perairan di Desa Wonorejo, Kabupaten Kendal memiliki kisaran suhu antara 27,86-29,5 ${ }^{\circ} \mathrm{C}$; salinitas sebesar 10-20 ppt; kedalaman antara 100-140 cm; kecerahan antara 25-40 cm; pH antara 7,9-8,6; kandungan oksigen terlarut (DO) sebesar 3,67-6,67 mg/l; kandungan nitrat lebih dari $4,5 \mathrm{mg} / \mathrm{l}$ dan kandungan fosfat antara 0,0394 $0,0758 \mathrm{mg} / \mathrm{l}$. Hasil pengukuran kualitas air tersebut sudah memenuhi persyaratan kelayakan budidaya udang vannamei sesuai pustaka. Menurut Mukherjee (2003), suhu untuk udang vaname berkisar antara $26-33^{\circ} \mathrm{C}$ dan optimal pada suhu $29-30^{\circ} \mathrm{C}$, salinitas berkisar antara $10-35 \mathrm{ppt}$ dan optimal pada kisaran $15-25 \mathrm{ppt}, \mathrm{pH}$ antara 7,5-8,7 dan optimal pada 8,0-8,5; DO antara 3-12 ppm dan optimal pada kisaran 4-7 ppm, kedalaman antara 1,2-1,5 m. Menurut Boyd and Clay (2002) konsentrasi nitrat di bawah $50 \mathrm{mg} / \mathrm{L}$ tidak membahayakan kehidupan udang. Keberadaan nitrat yang tinggi diperlukan untuk merangsang pertumbuhan klekap, plankton dan lumut sebagai pakan alami bagi udang, namun
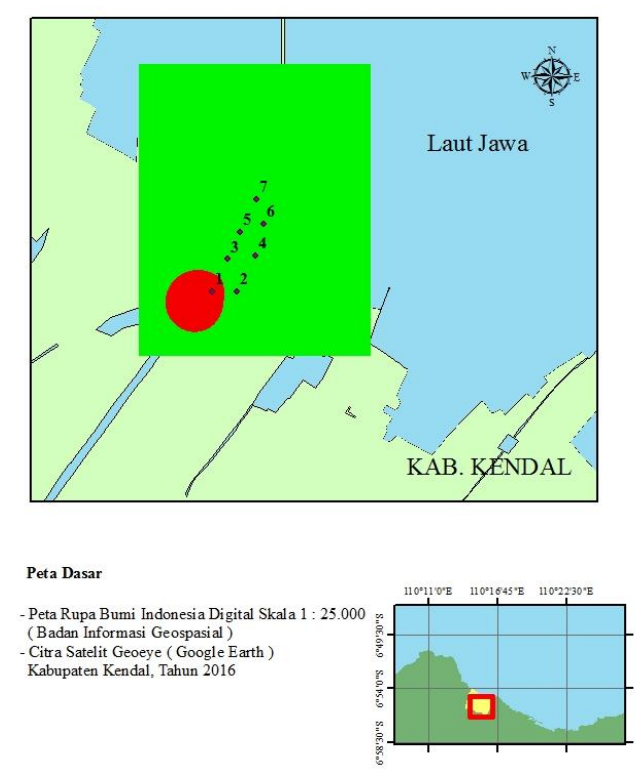

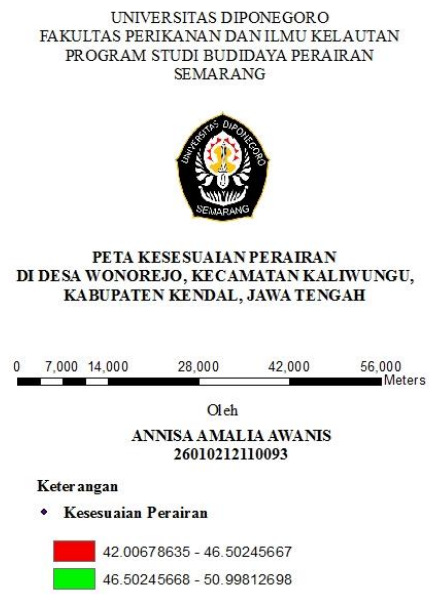

UNIVERSITAS DIPONEGORO
FAKULTAS PERIKANAN DANILMU KELAUTAN
PROGRAM STUDI BUDIDAYA PERAIRAN SEMARANG

$46.50245668-50.99812698$

Gambar 2. Peta kesesuaian lahan budidaya udang vaname di Desa Wonorejo, Kabupaten Kendal 
nitrat kurang diperlukan di teknologi udang intensif karena dikhawatirkan menyebabkan eutrofikasi dan goncangan kualitas air. Menurut Bathnagar et al., (2004), bahwa perairan dengan kadar fosfat sebesar $0,05-0,07 \mathrm{mg} / \mathrm{l}$ sudah optimum dan produktif. Fosfat merupakan senyawa yang terlarutdi dalam badan air atau perairan yang memiliki fungsi terhadap biota air misalnya pembentukan protein dan proses fotosintesis.

\section{Analisis potensi produksi berdasarkan kebutuhan oksigen}

Peningkatan suhu perairan sebesar $10^{\circ} \mathrm{C}$ dapat menyebabkan terjadinya peningkatan konsumsi oksigen oleh organisme akuatik sebesar 2-3 kali lipat. Namun peningkatan suhu seringkali disertai dengan penurunan kadar oksigen terlarut sehingga keberadaan oksigen terlarut tidak mampu memenuhi kebutuhan oksigen bagi organisme akuatik untuk melakukan proses metabolisme dan repirasi. Peningkatan suhu juga menyebabkan terjadinya peningkatan dekomposisi bahan organic oleh mikroba (Effendi, 2003).Adanya hubungan antara oksigen terlarut dengan suhu di perairan. Hubungan antara konsentrasi oksigen terlarut jenuh dan suhu pada tekanan udara 760 $\mathrm{mmHg}$ dapat dilihat pada tabel 4 .

Konsentrasi oksigen jenuh (saturasi) akan tercapai jika konsentrasi oksigen yang terlarut di perairan sama dengan konsentrasi oksigen terlarut secara teoritis. Konsentrasi oksigen tidak jenuh terjadi jika konsentrasi oksigen yang terlarut lebih kecil daripada konsentrasi oksigen secara teoritis. Kondisi super saturasi terjadi bila konsentrasi oksigen terlarut lebih besar daripada konsentrasi oksigen secara teoritis. Nilai saturasi pada setiap titik pengamatan dapat dilihat pada Tabel 5.

Tabel diatas merupakan hasil perhitungan dari saturasi pada setiap titik pengamatan. Nilai oksigen hasil pengamatan didapatkan dari pengamatan langsung dilapangan, sedangkan nilai oksigen hasil perhitungan didapatkan dari hasil perhitungan dengan menggunakan rumus. Nilai oksigen dari hasil pengamatan berkisar antara 3,67-6,67 mg/l, dengan nilai tertinggi terdapat pada titik 1 dan nilai terendah terdapat pada titik 6. Nilai oksigen hasil perhitungan berkisar antara $8,77-12,01 \mathrm{mg} / \mathrm{l}$, dengan nilai tertinggi terdapat pada titik 2 dan nilai terendah terdapat pada titik 7. Nilai saturasi didapatkan dari pembagian antara oksigen hasil pengamatan dibagi oksigen hasil

Tabel 4. Hubungan antara konsentrasi oksigen terlarut jenuh dan suhu pada tekanan udara $760 \mathrm{mmHg}$ (Cole 1983 dalam Pratiwi 2009)

\begin{tabular}{cccccc}
\hline Suhu $\left({ }^{\circ} \mathrm{C}\right)$ & $\begin{array}{c}\text { Konsentrasi } \mathrm{O}_{2} \\
\text { terlarut }(\mathrm{mg} / \mathrm{l})\end{array}$ & $\begin{array}{c}\text { Suhu } \\
\left({ }^{\circ} \mathrm{C}\right)\end{array}$ & $\begin{array}{c}\text { Konsentrasi O2 } \\
\text { terlarut }(\mathrm{mg} / \mathrm{l})\end{array}$ & $\begin{array}{c}\text { Suhu }\left({ }^{\circ} \mathrm{C}\right) \\
\begin{array}{c}\text { Konsentrasi O2 terlarut } \\
(\mathrm{mg} / \mathrm{l})\end{array}\end{array}$ \\
\hline 0 & 14,62 & 12 & 10,78 & 24 & 8,42 \\
1 & 14,22 & 13 & 10,54 & 25 & 8,26 \\
2 & 13,83 & 14 & 10,31 & 26 & 8,11 \\
3 & 13,46 & 15 & 10,08 & 27 & 7,97 \\
4 & 13,11 & 16 & 9,87 & 28 & 7,83 \\
5 & 12,77 & 17 & 9,66 & 29 & 7,69 \\
6 & 12,45 & 18 & 9,47 & 30 & 7,43 \\
7 & 12,14 & 19 & 9,28 & 31 & 7,30 \\
8 & 11,84 & 20 & 9,09 & 32 & 7,18 \\
9 & 11,56 & 21 & 8,91 & 33 & 7,06 \\
10 & 11,29 & 22 & 8,74 & 34 & 6,95 \\
11 & 11,03 & 23 & 8,58 & 35 & \\
\hline
\end{tabular}

Tabel 5. Nilai Saturasi Pada Setiap Titik Pengamanatan

\begin{tabular}{cccc}
\hline No Stasiun & Oksigen Hasil Pengamatan & Oksigen Hasil Perhitungan & Nilai Saturasi \\
\hline 1 & 3,67 & 11,03 & $46,8 \%$ \\
2 & 4,73 & 12,01 & $60,4 \%$ \\
3 & 5,48 & 10,22 & $69,9 \%$ \\
4 & 5,36 & 9,50 & $69,7 \%$ \\
5 & 5,14 & 8,40 & $66,8 \%$ \\
6 & 6,67 & 10,22 & $86,7 \%$ \\
7 & 6,42 & 8,77 & $84,9 \%$ \\
\hline
\end{tabular}



perhitungan kemudian dikalikan 100\%. Maka didapatkan nilai saturasi berkisar antara 46,8$86,7 \%$, dengan nilai saturasi tertinggi terdapat pada titik 6 dan nilai saturasi terendah terdapat pada titik 1.

Nilai saturasi yang didapatkan berkisar antara $46,8 \%$ - $86,7 \%$. Nilai saturasi tertinggi terdapat pada titik 6 yaitu $86,7 \%$, sedangkan nilai saturasi terendah terdapat pada titik 1 yaitu $46,8 \%$. Berdasarkan nilai konsentrasi oksigen terlarut yang diperoleh dari hasil pengamatan, didapatkan kadar oksigen yang terlarut lebih kecil daripada konsentrasi oksigen secara teoritis maka ini disebut konsentasi oksigen tidak jenuh. Effendi (2003) menyatakan bahwa kondisi tidak jenuh menggambarkan kadar oksigen terlarut di perairan lebih kecil daripada kadar oksigen yang terlarut secara teoritis berdasarkan nilai suhu pada tekanan udara $760 \mathrm{mmHg}$.

Nilai Oksigen hasil pengamatan berkisar antara 3,67 -6,67 mg/l. Sedangkan nilai oksigen hasil perhitungan atau secara teoritis untuk menghasilkan produksi 12 ton/hetkar pada lokasi penelitian berkisar antara 8,40 - 12,01 mg/l. Terjadinya selisih antara oksigen hasil pengamatan dan hasil perhitungan dikarenakan mungkin aerasi yang diberikan sangat kuat sehingga sisa oksigen yang dikonsumsi tidak banyak. Jika produksi 12ton/ha maka seharusnya ketersediaan oksigen harus mendekati saturasi, sementara yang teramati masih sekian persen dari saturasi. Jadi ini menunjukan bahwa aerasi yang digunakan pada lokasi penelitian tidak lebih ataupun tidak kurang hanya cukup saja.Tujuan dari aerasi itu sendiri adalah untuk pengkayaan oksigen dalam tambak, untuk menetralisasi aktivitas dari bakteri, untuk mengurangi kadar $\mathrm{CO} 2$ dan dekomposisi dari material organic yang mungkin dapat menyebabkan bau. Aerasi dapat menambah daya dukung dalam suatu sistem budidaya perairan, dimana oksien terlarut merupakan factor pembatas. Kandungan oksigen sangat berpengaruh terhadap pertumbuhan dan juga efisinsi pakan. Jika konsentrasi oksigen terlarut rendah, maka kultivan yang dibudidayakan tidak akan makan dengan baik, pertumbuhannya terhambat, akan rentan terkena penyakit dan bahkan bisa jadi menyebabkan kematian. Aerasi dibutuhkan untuk supplement sumber pakan alami. Menurut Mukherjee (2003), bahwa oksigen sangat diperlukan untuk produksi semua spesies ikan dan crustasea. Aerasi merupakan salah satu cara yang efektif untuk menambah nilai oksigen terlarut dalam suatu perairan.
Konsumsi oksigen udang dapat dipengaruhi oleh tingkat aktivitasnya pertumbuhan dan terjadinya pergantian kulit (molting). Pada udang muda (kecil) tingkat aktivitas relatif tinggi dibanding udang dewasa dan semakin tinggi aktivitas suatu individu maka laju metabolismenya juga akan meningkat. Karena kebutuhan akan energi semakin besar, sehingga konsumsi oksigennya juga akan tinggi. Proses moulting (pergantian kulit) juga mempengaruhi konsumsi oksigen udang vannamei. Dalam proses moulting udang vannamei memerlukan energi yang besar untuk melakukannya, sehingga perlu penyediaan cadangan energi yang cukup besar untuk melakukan moulting. Menurut Amri, (2003) moulting dilakukan udang untuk tumbuh, udang memiliki karapace keras dan tidak elastis sehingga harus diganti setiap terjadi pertambahan ukuran tubuh. Frekuensi pergantian kulit pada udang muda lebih sering terjadi, sementara pada udang dewasa jarang terjadi, ini berhubungan dengan laju pertumbuhan udang muda yang lebih cepat dibanding dengan udang dewasa. Lebih lanjut menurut Rubiyanto dan Dian (2005), proses moulting pada udang muda (fase tebar / PL-12) akan berlangsung setiap harinya, dan frekuensi moulting akan menurun / jarang seiring dengan pertambahan umur udang. Waktu yang diperlukan untuk moulting tergantung jenis dan umur udang, dalam prosesnya udang akan membutuhkan energi cukup besar, sehingga penyerapan oksigen akan meningkat pula.

\section{KESIMPULAN}

Kesimpulan yang dapat diambil dari hasil penelitian yang telah dilakukan di perairan Wonorejo, Kecamatan Kaliwungu, Kabupaten Kendal yaitu : Perairan Wonorejo, Kecamatan Kaliwungu, Kabupaten Kendal sesuai untuk budidaya udang vaname. Perairan ini memiliki wilayah yang termasuk dalam kategori Sesuai (S2) dengan luasan daerah yaitu 2 ha terdapat pada titik 1. Serta kawasan dengan kategoti sangat sesuai (S3) dengan luasan daerah yaitu 13,4 ha terdapat pada titik 2,3,4,5,6 dan 7. Ketersediaan oksigen pada lokasi penelitian cukup untuk budidaya udang vaname, jadi ketersediaan oksigennya menyucupi kebutuhan oksigen udang tidak melebihi ataupun kekurangan.

\section{REKOMENDASI}

Rekomendasi yang dapat diberikan dari penelitian ini yaitu perlu dilakukan penelitian berlanjutan secara temporal dan spasial sehingga kondisi kualitas perairan di Desa Wonorejo dapat 
terpantau dengan baik. Upaya yang perlu dilakukan agar titik yang sesuai bisa masuk kedalam kategori sangat sesuai antara lain bisa dari kedalamannya yang kita perbaiki, dan salinitasnya kita tinggikan, dan untuk titik yang sudah masuk kedalam kategori sangat sesuai upaya yang bisa kita lakukan untuk mempertahankannya adalah selalu mengontrol kualitas perairannya agar tetap stabil.

\section{UCAPAN TERIMA KASIH}

Terima kasih penulis ucapkan kepada Pak Hanif yang telah memfasilitasi dan membantu dalam penelitian dan teman-teman yang telah membantu dalam proses penelitian.

\section{DAFTAR PUSTAKA}

Amri, K. 2003. Budidaya Udang Windu Secara Intensif. Agromedia Pustaka. Jakarta.

Bhatnager, A., S.N. Jana, S.K. Grag, B.C. Patra, G. Singh and U.K. Barman. 2004. Water Quality Management in Aquaculture in Course Manual of Summer School on Development of Sustainable Aquaculture Tecnology in Fresh and Salic Water. CCS Haryana Agriculture, Hisar. India. pp.203210.

Boyd, C.E. and J.W. Clay. 2002. Evaluation of Belize Aquaculture, Ltd: A Superintensive Shrimp AquacultureSystems. Report prepared under the World Bank, NACA, WWF and FAO Consortium Program on Shrimp Farming and the Environment. Work in Progress for Public Discussion. Published by the Consortium. $17 \mathrm{p}$.

Cahyono, B. 2009. Budidaya Biota Air Tawar. Kanisius. Yogyakarta.

Dinas Perikanan dan Kelautan Kabupaten Kendal. 2006. Laporan Produksi Perikanan Kendal 2005. Dinas Perikanan dan Kelautan Kabupaten Kendal. Kendal.

Effendi, H. 2003. Telaah Kualitas Air Bagi Pengelolaan Sumber Daya dan Lingkungan Perairan. Fakultas Perikanan dan Ilmu Kelautan. Institus Pertanian Bogor. Bogor. $259 \mathrm{hlm}$.

Hartoko A. dan Alexander K. 2009. Spasial Modeling For Marine Culture Site Selection Based On Ecosystem Parameters At Kupang Bay, East Nusa Tenggara-Indonesia. Int. J. Remote Sensing Earth Science., 6:57-64.

Kingzett, B. Salmon, R. 2002. First Nation Shellfish Aquaculture Regional Business Strategy. Kingzett Professional Services Ltd. British Columbia, Canada.
Mukherjee, S.C. 2003. Short-term Training Programme On Aquaculture Engineering. Central Intitute of Fisheries Education. Mumbai.

New, M.B. 2002. Freshwater Prawn Farming A Manual For The Culture Of Macrobrachium Rosenbergii. Fisheries Technical. Food and Agriculture Organization of the United National. 428 p.

Pratiwi, A. 2009. Pengaruh Pencampuran Masa Air Terhadap Ketersediaan Oksigen Terlarut Pada Lokasi Keramba Jaring Apung Di Waduk Ir. H. Juanda Purwakarta. [Tesis]. Fakultas Perikanan dan Ilmu Kelauta. Institut Pertanian Bogor. Bogor

Ramadhani, F., Syahrul, P., dan T, Krairuman. 2016. Analisis Kesesuaian Parameter Perairan Terhadap Komuditas Tambak Menggunakan Sistem Informasi Geodrafis (SIG) Di Kabupaten Pidie Jaya. Program Studi Ilmu Kelautan dan Perikanan. Universitas Syiah Kuala Darussalam. Banda Aceh.

Romadhona, B., Y. Bambang dan Sudarno. 2015. Fluktuasi Kandungan Amonia Dan Bebas Cemaran Lingkungan Tambak Udang Vaname Intensif Dengan Teknik Panen Parsial Dan Panen Total. Fakultas Perikanan dan Ilmu Kelautan. Universitas Diponegoro. Semarang.

Rubiyanto, W. H., dan Dian A. S. 2005. Udang Vannamei, Penebar Swadaya, Jakarta.

Wibowo, H. 2006. Cara Memilih Benur Udang Vaname Berkualitas. Balai Benih Air Payau Situbondo. Situbondo.

Widiatmaka, A. Sutandi, I. Anas, U. Daras, M. Hikmat and A. Krisnohadi. 2014. Establishing Land Suitability Criteria For Cashew (Anacardiumoccidentale L.) in Indonesia. J. Appli. Environ. Soil Sci. 1-14, http:// dx.doi.org/10.1155/2014/743194

Widiatmaka, W. Ambarwulan, B. Riadi, I. Nahib, S. Budhiman and A. Halim. 2014. Spasial Multi Criteria Land Evaluation and Remote Sensing for Area Delineation of Shrimp Pond Culture Revitalization in Mahakam Delta, Indonesia. Proceeding of the $12^{\text {th }}$ Biennial Conference of Pan Ocean Sensing Conference (PORDEC 2014). Bali. Indonesia. pp: 839-847.

Yasin, M. 2013. Analisa Ekonomi Usaha Tambak Udang Berdasarkan Luasan Lahan di Kabupaten Parigi Moutong Provinsi Sulawesi Tengah. Jurnal Ilmiah. Agribisnis. 